\title{
EL CLAUSTRO DEL COLEGIO DE CORPUS CHRISTI DE VALENCIA. ANÁLISIS FORMAL Y COMPOSITIVO
}

\author{
POR \\ JORGE LLOPIS VERDÚ \\ Universidad Politécnica de Valencia
}

El Colegio del Corpus Christi, construido a finales del siglo XVI es la obra personal del Patriarca San Juan de Ribera y su claustro la más significativa obra renacentista de la ciudad de Valencia. En su concepción arquitectónica juega un papel fundamental un lote de columnas adquiridas en Italia por el Duque de Pastrana, a partir de las cuales y de las propuestas formales y dimensionales de Serlio y Vignola, se desarrolló un proyecto de autor desconocido que evidencia el nivel de asimilación de los principios de la arquitectura renacentista en la Valencia del siglo XVI.

Palabras Clave: Arquitectura siglo XVI; Colegio; Patriarca; Serlio; Vignola; Valencia

The College of Corpus Christi, constructed at the end of the 16th century, is the personal project of the Patriarch San Juan de Ribera, and its cloister is the most significant Renaissance structure in the city of Valencia. A group of columns acquired in Italy by the Duke of Pastrana played a fundamental role in the conception of this architectural structure. The unknown architect based his project on them as well as on the formal and dimensional concepts of Serlio and Vignola. The result is proof of the level of assimilation of the principles of Renaissance architecture in 16th-century Valencia.

KEY wORDs:16th century architecture. College. Patriarch. Serlio. Vignola. Valencia.

El Colegio de Corpus Christi es, probablemente, la más acabada obra arquitectónica del Renacimiento valenciano. Representa el punto final de un camino, el del conocimiento y aprendizaje de las variables formales renacentistas y la sustitución de las formas arquitectónicas medievales por un nuevo lenguaje que termina por desplazar completamente las elementos formales góticos, sustituyéndolos por un conjunto de formas extraídas de la arquitectura del clasicismo greco-romano, y reelaboradas en un lenguaje nuevo. Su construcción se sitúa cronológicamente en el punto final del proceso de asimilación, cuando el Renacimiento ya no es una novedad importada, propia de espíritus cultos que gustan de las novedades, sino un lenguaje común a todos nuestros artífices. El camino de implantación de las formas clásicas, que está jalonado por obras tales como el Convento de Santo Domingo y la Sacristía y Capilla Mayor de la iglesia de Santiago de Orihuela -obra de Jerónimo Quijano-, el Hospital General de Valencia -de Gaspar Gregori-, o el lento proceso de construcción del Monasterio de San Miguel de los Reyes, culmina en el clasicismo desornamentado del Colegio del Patriarca. 
El Colegio de Corpus Christi está indisolublemente unido a la figura del que fuera su fundador y decidido impulsor: don Juan de Ribera (fig. 1), Arzobispo de Valencia y Patriarca de Antioquia1, quien emprendería la obra en cumplimiento de un mandato expreso realizado por el Concilio de Trento, finalizado el año $1562 .^{2}$

\section{El Colegio de Corpus Christi}

El edificio del Colegio de Corpus Christi se inscribe en un cuadrilátero irregular que ocupa una manzana completa del centro de Valencia, constituida por las calles de la Nave, de la Cruz Nueva, Cardenal y San Juan de Ribera (fig 2), con unas dimensiones aproximadas de 47 metros de fachada, por 50 metros de profundidad. Su ubicación responde a su proximidad con la Universidad de Valencia, ya que ambos enfrentan sus fachadas en la estrecha calle de la Nave, con lo que se conseguía que los colegiales pudiesen asistir fácilmente a las clases de teología. El edificio se erigió sobre solares anteriormente ocupados por el Call o Judería de Valencia, cuyo asalto y destrucción tuvo lugar en $1391 .^{3}$

El día 14 de marzo del año 1583 se procede, mediante carta entregada ante el notario Hieronimo Metaller, "notario scrivano publico en la dicha Ciudad y reyno de Valencia", a la fundación del Colegio de Corpus Christi ${ }^{4}$. En la misma, además de exponer los motivos religiosos que impulsan la fundación colegial, se precisa que en el momento del inicio de la construcción todavía no se había terminado el proceso de compra de las casas afectadas. A este respecto hay que señalar que la compra de inmuebles se inició el 7 de octubre del año 1580, si bien existe constancia de compra de casas en fechas sucesivas, como por ejemplo los años 1583,1586 y 1595.5

También se referirá el Patriarca Ribera a la obra arquitectónica propiamente dicha. No existe mención alguna al autor o los autores del proyecto, pero se refleja el hecho de que existía o estaba prevista la existencia de una traza, puesto que la obra debía realizarse "conforme a la traça y designo que para ello mandaremos y senyalaremos el qual prometemos y nos obligamos dar" 6 . El tema parece especialmente interesante para nuestro propósito, pues aparece con cierta frecuencia en los contratos de los diversos constructores que trabajaron en la obra, en los que desde el principio parece quedar firmemente asentado el control del Patriarca Ribera sobre las características arquitectónicas del edificio

Lo cierto es que en el Archivo del Colegio de Corpus Christi (A.C.CH.) existe constancia cierta de haberse realizado trazas del conjunto para ser enviadas a la familia Gondi, en Francia, conservándose los

\footnotetext{
${ }^{1}$ Escriva, Francisco. Vida del Illustrisimo y Excellentissimo Señor Don Juan de Ribera, Patriarcha de Antioquía y Arçobipo de Valencia, 1612.; Busquets Matoses, Iacinto. Idea Exemplar de Prelados Delineada en la Vida, y Virtudes del Venerable Varon el Illmo y Excmo Señor D. Juan de Ribera, Patriarca de Antioquia. 1683; y RoBres Lluch, Ramón. San Juan de Ribera, Patriarca de Antioquía, Arzobispo y Virrey de Valencia: 1532-1611. (Un obispo según el ideal de Trento). Barcelona. 1960.

2 De hecho el proceso de erección de Colegios y Seminarios era un tema que centraba la atención tanto de los diversos obispados como de la Corona española, que el 12 de Julio del año 1564 había publicado las disposiciones del Concilio de Trento bajo la forma de ley de Estado en España por medio de una Real Cédula (Ley XIII, tit.I, Novis. Recopil). Sobre este proceso ver Fernandez Conde, Manuel. España y los seminarios tridentinos. C.S.I.C., Madrid, 1948.

${ }^{3}$ Sobre la historia y las características de la Judería valenciana ver: RoDRIGO Y PERTEGÁs, JosÉ. La Judería de Valencia. Hijos de Vives Mora, Valencia, 1913. y Roca Traver, Francisco A. Los judíos valencianos en la Baja Edad Media. Ayuntamiento de Valencia, Valencia, 1998. pp. 317-320

${ }^{4}$ La carta original se conserva, depositada en el Archivo del Colegio (Arch. del mismo perg. A, sign. I,7), y constituye un testimonio básico para comprender tanto los móviles de la fundación, como el proceso emprendido para la misma.

5 Boronat y Barrachina, Pascual. El Beato Juan de Ribera y el Real Colegio del Corpus Christi. Valencia. 1904. pp.29-30.

6 "Escritura de fundación del Real Colegio de Corpus Christi". (A.C.CH. perg. A, sign.I,7)
} 
recibos de los pagos efectuados por las mismas ${ }^{7}$. Las facturas están fechadas en diciembre de 1602 y octubre de 1603, y se refieren, respectivamente, a una planta y traza del conjunto formado por la iglesia y el Colegio, y la capilla de Nuestra Señora la Antigua; es decir, una traza global, y una traza parcial. Las fechas evidencian que son trazas posteriores a las obras, por lo que cabe concluir que no se trata de dibujos pertenecientes al proceso de ideación proyectual.

Sin embargo, el empleo de trazas para el control formal del proceso constructivo está fehacientemente contrastado en el caso del Colegio, ya que así aparece descrito en diversos contratos para la ejecución constructiva del edificio. La primera referencia la encontramos en el contrato firmado el 16 de julio de 1590 por Guillem del Rey para la construcción de la capilla del Colegio de Corpus Christi, donde aparecen numerosas referencias a la existencia de unas trazas, tanto en planta como en alzado, a las que el constructor debía sujetarse fielmente, sin margen alguno de libertad. Queda meridianamente claro el alcance de las trazas elaboradas, ya que en las mismas se debía contemplar detalladamente tanto las dimensiones globales, como el diseño de los elementos ornamentales propios de los órdenes, incluida la dimensión de cornisas y molduras. Sin embargo, cuando hay que construir elementos parciales, tales como puertas, se hace referencia a una traza que se le facilitará posteriormente.

También en el caso del contrato firmado por el mismo Guillem del Rey para la construcción del claustro del Colegio, fechado en noviembre de 1599, se da esta misma circunstancia. En el momento de la firma de dicho contrato, se le entrega a Guillem del Rey una traza del mismo, lo que se desprende de las referencias contenidas en el texto, de las que la cláusula siguiente puede servirnos de ejemplo: "Ittem que el dicho Guillem del rey ha de asentar todas las columpnas baças y chapiteles de marmol y todo lo demas de la obra del dicho claustro hasta quedar aquel acabado con su devida perfection conforme a la traça y capitulos de aquella" 8 . Y lo mismo acontece en el caso de los contratos firmados por Francisco Figuerola "para la ornamentación de la Iglesia del Colegio de Corpus Christi” 9 , fechado el 5 de julio de 1598, y por Gaspar Bruel "para la construcción de una puerta de jaspe en el crucero de la Iglesia del Colegio de Corpus Christi" 10 , cuya traza, a diferencia de las anteriores, sí se ha conservado (fig. 3).

Como puede verse, queda suficientemente contrastado el empleo de trazas previas en el proceso constructivo del Colegio de Corpus Christi, lo cual resultaba totalmente previsible dado los usos arquitectónicos de la época.

La metodología proyectual arquitectónica del siglo XVI ha sido estudiada por diversos autores. Al principio el arquitecto entregaba una traza general, lo que permitía valorar el conjunto y comenzar los procesos de construcción y de cimentación; posteriormente el arquitecto iba entregando trazas parciales, conforme el proceso constructivo lo iba demandando. Juan de Herrera es el responsable de la modificación de esta manera de proceder, ya que siguiendo su método de trabajo, se entregaban todos los datos necesarios para la construcción del edificio, lo que por primera vez separaba radicalmente los procesos de ideación y de construcción de la obra arquitectónica ${ }^{11}$. Pese a lo tardío de su construcción, el proceso de erección del Colegio del Patriarca debió parecerse más a la primera metodología que a la metodología herreriana, con la entrega inicial de una

7 "Señor Mosen Agorreta V.M. mandara pagar Amester Martín Dominguez carpintero cien reales castellanos por una Planta y traza de la yglesia y Colegio del patriarca mi señor para enbiar Afrancia. A guondy fecho a ventiquatro dias Del mes de Deciembre 1602.", y "Señor, mosen Agorreta V.M. mandara pagar Amose Martin Dominguez Carpintero veinte Reales castellanos por dos trazas que yzo dela capilla de nuestra señora la Antigua para abiar ha Gondi Afrancia y por unos adobos deunas vidrieras del canborio y por la verdad yze la presente cedula echo savado A 11 de Hotubre 1603.". A.C.Ch. 1,4,25. y Libro de Fábrica del Colegio de Corpus Christi.

8 "Concierto firmado por Guillem del Rey para la construcción del claustro del Colegio de Corpus Christi". (A.C.Ch: I,6,1,80).

9 "Concierto firmado por Francisco Figuerola para la ornamentación de la Iglesia del Colegio de Corpus Christi". (A.C.Ch: I,6,1,10)

10 "Concierto firmado por Gaspar Bruell para la construcción de una puerta de jaspe en el crucero de la Iglesia del Colegio de Corpus Christi" (A.C.Ch: I,6,1,11)

11 V.V.A.A Las trazas de Juan de Herrera y sus seguidores. Patrimonio Nacional, s.f. 
traza general y realización posterior de trazas parciales y de detalle. La consecuencia lógica es una menor integración formal de las partes, y una visión más fragmentada del conjunto.

Si el empleo de trazas generales y parciales en el proceso de construcción del Colegio de Corpus Christi parece suficientemente demostrado, la identidad de la persona o personas responsables de las mismas, ya no resulta tan evidente. Son diversas las hipótesis planteadas por los diversos autores, si bien las más divulgadas serían la referente al papel directo jugado por el propio Patriarca Ribera, o la propuesta que propone la autoría del arquitecto valenciano Gaspar Gregori. La primera hipótesis derivada del paralelismo establecido por diversos autores entre el Monasterio del Escorial y el Colegio del Patriarca, propondría que el auténtico ideador del conjunto sería el propio Patriarca Juan de Ribera, que posteriormente se apoyaría en arquitectos para llevar a la práctica sus propias ideas. Esta hipótesis aparece por vez primera explícitamente planteada por Franco Sena i Chocomeli (1868) ${ }^{12}$, y se vería reforzada por el propio Patriarca cuando señala en las Constituciones del Colegio, que "hemos reservado algunas opiniones propias para executarlas en esta iglesia" "13. Todo esto demostraría la existencia de una voluntad cierta de intervenir en aspectos puramente arquitectónicos, en concordancia con las directrices de Carlos Borromeo, quien en su obra Instructiones Fabricae et suppellectilis Eclesiasticae (Milán, 1577), que el Patriarca poseyó y conoció ${ }^{14}$, establece que el obispo debe intervenir activamente en la concepción de las iglesias que se construyen en su diócesis, cuidándose de todos aquellos aspectos que pueden influir en la liturgia que se desarrolla en los mismos, en un esquema en el que el arquitecto queda reducido a poco más que ejecutor de las directrices marcadas por el obispo.

La segunda hipótesis, planteada por J. Berchez y M. Gómez-Ferrer ${ }^{15}$, defiende la autoría puramente arquitectónica, centrada en la figura de Gaspar Gregori, sin lugar a dudas la figura más sobresaliente del panorama arquitectónico renacentista valenciano y el primero al que cabría denominar como arquitecto en el sentido renacentista del término. Su conocimiento de la teoría arquitectónica renacentista, y su manejo de la nueva metodología proyectual está documentalmente contrastada ${ }^{16}$. De hecho, el nombre de Gaspar Gregori aparece repetidamente en el contrato firmado por Guillem del Rey para la construcción de la iglesia, si bien en consideración de inspector, nunca de tracista. Todo esto podría suponer la supervisión por parte de Gaspar Gregori de su propio proyecto, ya que nadie mejor que él estaría calificado para realizarlo. Por contra sorprende el hecho de que si Gregori llegó a tener un papel de tal importancia en la concepción del Colegio, su nombre tan solo aparezca en esta ocasión en un archivo tan completo y bien conservado como el del Colegio de Corpus Christi, lo que convierte esta hipótesis, tan sugestiva como coherente, en difícilmente demostrable.

Lo único cierto es que un estudio de la información documental del archivo avala antes la hipótesis de la fragmentariedad que la de la unicidad proyectual. La obra se acometió por fases, a través de contratas parciales encomendadas a diversos autores, sin que parezca existir una relación entre los mismos y entre los trabajos sucesivamente desarrollados. Según este esquema, si existió una traza global no sería en el sentido de considerar la existencia de un proyecto unitario, a la manera de la metodología puesta en marcha por Herrera

\footnotetext{
12 Sena Chocomeli Y Llobell, Franco. Reseña histórica del Real Colegio de Corpus Christi, fundado por el Beato Juan de Ribera, Patriarca de Antioquía, Arzobispo, Virrey y Capitán General de Valencia. Valencia. 1868. p.11.

13 "Constituciones del Colegio y Seminario de Corpus Christi". 1732. cap. XLI. "De lo que toca a la Fábrica de los Retablos y Altares".

14 Sobre las bibliotecas del Patriarca Ribera los estudios fundamentales son los realizados por Vicente Cárcel Ortí: "Obras impresas del siglo XVI en la Biblioteca de San Juan de Ribera", en Anales del Seminario de Valencia, VI, 1966, n111, pp.111-383; e "Inventario de la Biblioteca de San Juan de Ribera en 1611". Analecta Sacra Tarraconensis, vol. XXXIX, Barcelona, pp.319-379.

15 Berchez, Joaquín y Gomez-Ferrer, Mercedes. "Real Colegio de Corpus Christi o del Patriarca". Monumentos de la Comunidad Valenciana: Catálogo de Monumentos y Conjuntos declarados e incoados. Tomo X. Valencia, 1995. pp.156-171

16 Llopis Verdú, J. “Gaspar Gregori y la introducción de la metodología proyectual renacentista en Valencia”, EGA, nº 2002, pp.48-59.
} 
en la Corte, sino que podría tratarse tan solo de una distribución de las partes en el solar, pero sin el grado suficiente de definición para ejecutar la obra a partir de las mismas. A partir de este esquema global se irían desarrollando trazas parciales según avanzaba la obra.

Es mediante este proceso fragmentario de proyectación que se desarrolla un esquema planimétrico tradicional en la tipología de los colegios de la época, formado por dos espacios principales (capilla y claustro), en torno a los que se articulan el resto de las dependencias. Pero lo más interesante desde nuestro punto de vista es la individualidad de los dos espacios principales, entre los cuales las analogías formales y compositivas son escasas (fig 4).

\section{El claustro del Colegio del Corpus Christi}

El claustro del Colegio de Corpus Christi (fig. 5) ha sido considerado la obra más acabada del clasicismo renacentista valenciano: el punto de llegada del proceso de asimilación formal del nuevo lenguaje en unas tierras con una rica herencia constructiva medieval. Su estructura compositiva remite al esquema tradicional de apoyo directo del arco sobre la columna, en detrimento del uso del ortodoxo sintagma albertia$n o$, en el que la doble relación arco-muro y columna-entablamento, representa el modelo formal de superposición canónica, que iría abriéndose paso a lo largo del siglo XVI en el conjunto de la arquitectura europea. Para el análisis de su concepción resulta básico el hecho de que las columnas que lo forman no fueran realizadas expresamente para el mismo, sino que fueron adquiridas por el Patriarca Ribera a la familia del Duque de Pastrana, que las tenía enterradas en los puertos de Cartagena y Alicante a la espera de utilizarlas en la construcción de un palacio ${ }^{17}$.

El año 1596 se inicia el proceso de adquisición de las columnas, siendo este dato perfectamente constatable con la información estudiada del Archivo, más exactamente en un documento contenido en el mismo y titulado posteriormente "Sobre las columnas" ${ }^{18}$. El transporte de las piezas desde el puerto de Alicante debió realizarse de forma inmediatamente posterior al acuerdo de compraventa; otro caso radicalmente diferente es el del transporte de las piezas de mármol conservadas en Cartagena, proceso en el que debieron surgir problemas desde su inicio. Tan solo hemos localizado un recibo referente a dicho transporte, y su texto no es definitivo ${ }^{19}$, ya que no refleja el transporte real de la mercancía. El documento revela que el traslado de las piezas de mármol conservadas en Alicante ya ha sido efectuado y se encuentran depositadas en Valencia, mientras que el traslado de las piezas de Cartagena se encontraba en este punto congelado, más de dos años después del acuerdo inicial de venta, al encontrarse dichas columnas embargadas. Inmediatamente después del acuerdo alcanzado entre el Patriarca y el apoderado de la Duquesa de Pastrana, se inician los trámites para resolver el embargo que pesa sobre las columnas, y el día siguiente al de la firma de dicho acuerdo, el Patriarca extiende poderes al Maestro Alonso Orts para que se desplace a Cartagena a resolver el problema ${ }^{20}$, lo que muestra claramente la urgencia que se tenía en proceder a las obras de construcción del

${ }^{17}$ En el Archivo del Colegio de Corpus Christi se conserva la siguiente información relativa al proceso de compra de las columnas: "Poderes para vender a Mo Vo $S^{o} r$ las columnas y demás de la casa de Pastrana" (A.C.CH. I,6,3,6); "Sobre las columnas" (A.C.CH. I,6,1,1); "Poder para recibir las columnas, basas y chapiteles a Alonso Orts" (A.C.CH. I,6,1,20); "Visura y justiprecio de las columnas, basas y chapiteles practicado en esta ciudad" (A.C.CH. I,6,3,7); "Carta de Venta de las columnas del claustro" (A.C.CH. I,6,3,7).

${ }^{18} \mathrm{El}$ documento está redactado ante el notario Nuñez de Barques "del consejo de su magestad y de la Santa Inquisición”, y se trata de una carta redactada con fecha 28 de Abril de 1599, tratándose de un acuerdo firmado por el propio don Juan de Ribera con don Carlos Joan de Torres, que durante todo el proceso actuaría como procurador de "doña Anna Portugal y Borja viuda mujer que fue de don Rodrigo de Silva y Mendoça Principe de Melito y Duque de Pastrana". A.C.CH.-I,6,1,1.

${ }^{19}$ Se trata de un recibo que se emite "aquenta del primer viatje de quarenta columnas que se han de traer de cartagena para el collegio", (A.C.CH.: I, 6, 1, 20.)

20 "Poder para recibir las columnas, basas y chapiteles" A.C.CH.- I, 6, 1, 20. 


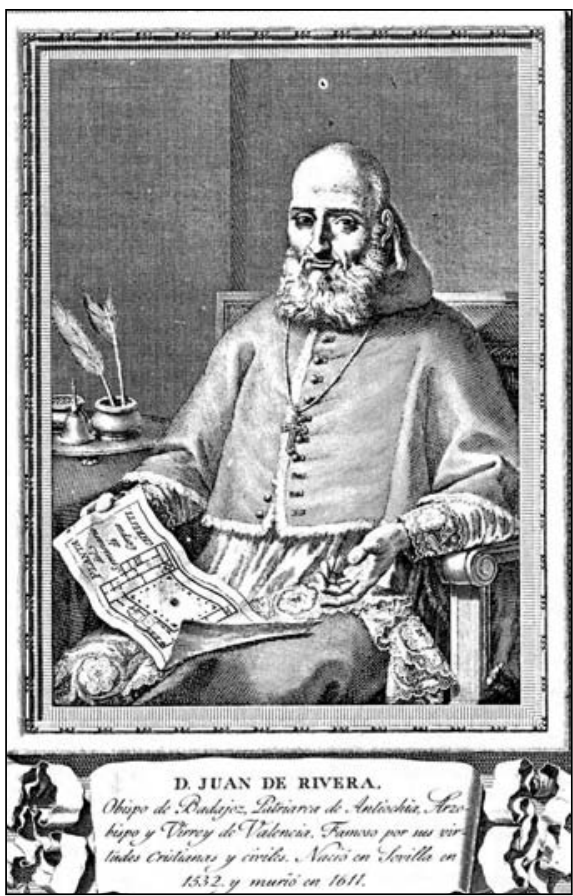

Fig. 1. Retrato del Patriarca Ribera con el plano del Colegio de Corpus Christi (F. Selma).

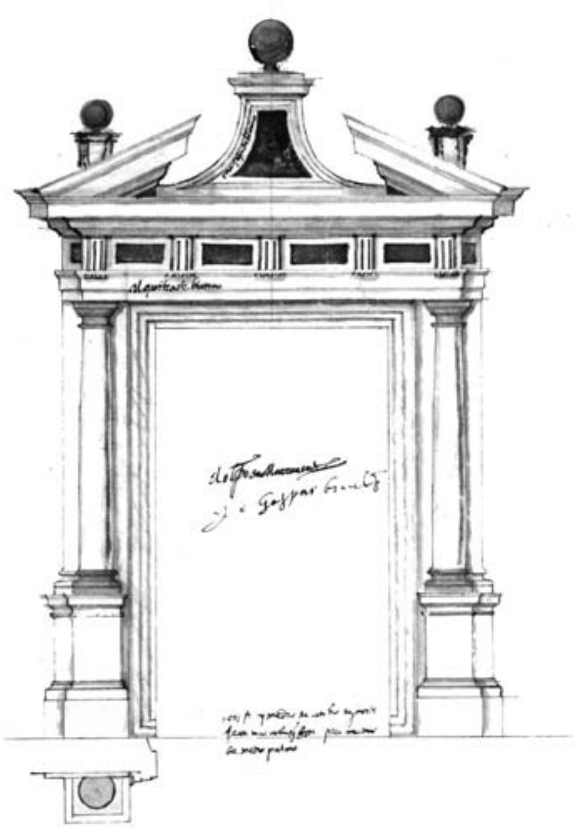

Fig. 3. Traza de la portada de la capilla de San Mauro, firmada por Gaspar Bruel. (1599).

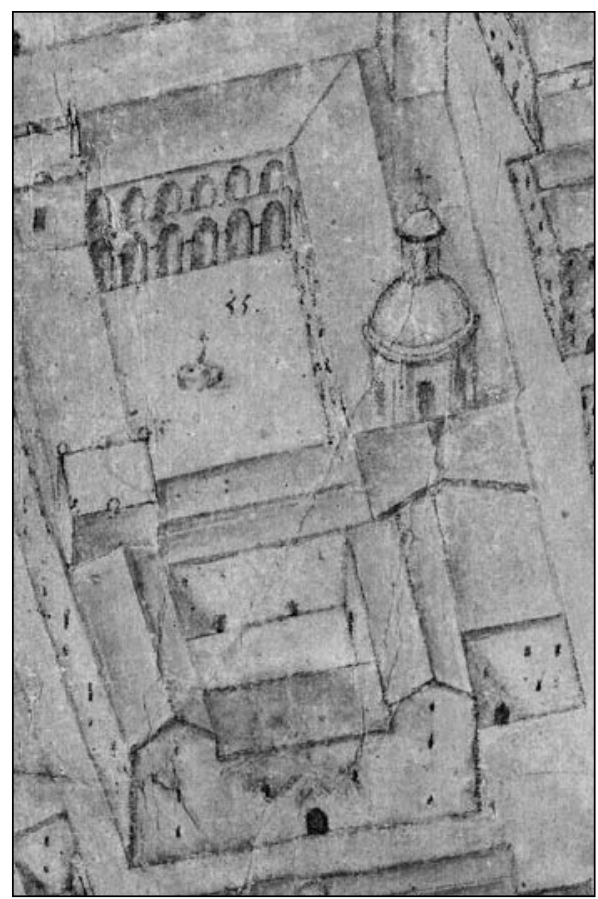

Fig. 2. El Colegio de Corpus Christi en el plano delineado por el Padre Tosca. (1704) .

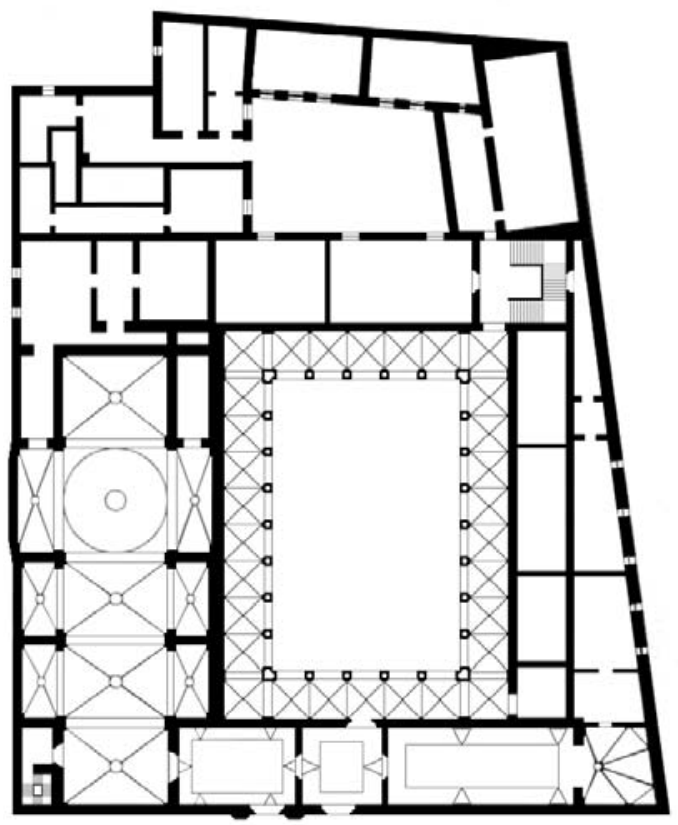

Fig. 4. Planta del Colegio de Corpus Christi de Valencia. 
claustro. Ya con fecha 23 de Agosto de 1599 se extenderá la definitiva carta de pago, de forma que en dicha fecha todo el lote de columnas se encuentra definitivamente en Valencia, transportado, inspeccionado y tasado por los peritos del Patriarca, dándose fin de esta manera al largo proceso de compra.

Es en este punto, una vez transportadas y entregadas la totalidad de las piezas de mármol, en que se procede al recuento y tasación, en los términos que a continuación reproducimos:

\begin{tabular}{cccc} 
No COLUMNAS & Tipo & BASAS & CAPITELes \\
\hline 38 & GRANDES (Dóricas) & 12 & 10 \\
29 en buen estado & & \\
9 muy gastadas & PEQUEÑAS (jónicas) & 32 & 29 \\
\hline $\begin{array}{c}37 \\
28 \text { en buen estado } \\
9 \text { muy gastadas }\end{array}$ & & y 1 para adobos \\
\hline 75 COLUMNAS & TOTAL & 44 BASAS & 40 CAPITELES \\
\hline
\end{tabular}

En cuanto al estado de conservación de las columnas adquiridas, podemos analizar las conclusiones del informe técnico realizado para la valoración definitiva de las mismas, efectuado el 26 de Julio del mismo año 1599 por los pedrapiqueros Francisco Figuerola, Vicente Esteban y Pedro García. En el referido informe destacan las consideraciones realizadas sobre las 9 columnas dóricas y las 9 jónicas que según los expertos estaban muy estropeadas. Dichas columnas, siempre según el citado informe, "no pueden servir para carga sino para estar arrimadas a una pared", por lo que serían las utilizadas en la cantoneras del claustro o en otras partes que no necesitasen una alta capacidad portante, tales como la portada o los retablos. Según este razonamiento, una vez eliminadas las 9 columnas de cada orden que no se encontraban en condiciones, tendríamos 29 columnas dóricas y 28 columnas jónicas en perfecto estado; suficientes para las cubrir las necesidades de 22 columnas dóricas y otras tantas jónicas exentas, mientras que para las 8 columnas de cada orden necesarias para la construcción de los cantonales pudo recurrirse a las peor conservadas (fig. 6).

Es a partir de este material previo que se procede al diseño y construcción del espacio claustral, y resulta especialmente importante fijar el hecho de que el lote de columnas adquirido no estuvo a disposición de los ideadores de la obra hasta bien avanzado el proceso constructivo, por lo que no pudo formar parte de las primeras decisiones de proyecto, y tuvo que procederse a un diseño “adaptativo", en el que se ajustó el diseño a las condicionantes previos y a las características dimensionales y compositivos de las columnas adquiridas, según contrato firmado entre el maestro Guillem del Rey y el Rector del Colegio don Miguel de Espinosa para la construcción del claustro, fechado el 26 de Noviembre de 1599, es decir, tan solo tres meses después de solucionada definitivamente la compra.

Cuando comienza la construcción del claustro, una parte importante de las edificaciones del Colegio se encuentran muy avanzadas. Es el caso de la Iglesia comenzada por el mismo Guillem del Rey con fecha 16 de Julio de 1590, y continuada en lo referente a la ornamentación y pavimentado según un contrato de fecha 1 de Agosto de $1596^{21}$. Una segunda actuación que debió condicionar el comienzo de las obras del claustro fue la construcción del cuerpo de la fachada principal, recayente a la calle de la Nave, cuya obra había sido encomendada a Miguel Rodrigo y Antonio Marona, firmándose el contrato con fecha 8 de Junio de $1593^{22}$. Ambas construcciones debían condicionar notablemente las dimensiones y características del espacio claustral, tanto en lo referente a las alturas de forjado, como en lo referente a las dimensiones generales

${ }^{21}$ Los documentos a que se hace referencia son: "Concierto firmado por Guillem del Rey para la construcción de la Iglesia del Colegio del Corpus Christi.". (A.C.CH.: I, 6, 1, 6). Anexo-IX; "Concierto firmado por Guillem del Rey para la terminación de la Iglesia del Colegio del Corpus Christi y la construcción de la puerta de la Capilla del Monumento". (A.C.CH.: I, 6, 1, 7). Anexo-X

22 "Concierto firmado por los maestros Miguel Rodrigo y Antonio Marona para la construcción de la parte del Colegio del Corpus Christi recayente a la calle de la Nave”. (A.C.CH.: I, 6, 1, 5). Anexo-VIII. 
del conjunto. De hecho ambas iban ya ligadas dimensionalmente desde el inicio, lo que no podía ser de otra manera, dadas las necesidades de integración entre ambas. Así, en el contrato de construcción del ala de la fachada del edificio, se estipulaba la altura de forjado en función de la iglesia, diciéndose literalmente lo siguiente: "Item ha sido pautado, havenido y concordado entre las dichas partes que se haya de tornar a tapiar el mismo hilo que se ha de derribar para assentar la primera cubierta de esta manera, que se hayan de encaxar los reboltones en la tapia que se hara nueva tomando el nivel del alto del coro y que vengan a nivel los dos paymentos". Como se puede ver, las especificaciones hacen referencia al nivel del coro de la iglesia, y consecuentemente al nivel de las celdas del edificio recayentes a la fachada principal.

Lo cierto es que ambas obras se encontraban terminadas en el momento del inicio de la construcción del claustro. La fachada principal, encomendada a Rodrigo y Marona, debió ser terminada en febrero de 1595, y revisadas por los maestro Guillem Salvador, Luis de Gurrea, Antonio Corverán y Juan Castellano. En lo referente a la conclusión de las obras de la iglesia, no se ha encontrado una referencia precisa, aunque resulta claro que dado que el segundo contrato firmado por Guillem del Rey se refiere exclusivamente a cuestiones de acabado, las obras incluidas en el primer contrato, que son las estructurales, habían sido previamente finalizadas.

Además, hay datos que potencian la creencia de que el resto de los cuerpos de edificación habían sido ya concluidos, o al menos estaban en ese momento en construcción. Nos estamos refiriendo a los otros dos cuerpos de edificación que definen el espacio del claustro. Así, hay que destacar que simultáneamente a los trámites para concluir el proceso de compra de las columnas de la familia del Duque de Pastrana, comienzan las primeras intervenciones ligadas a la construcción de la escalera principal del edificio. El contrato para la construcción de la escalera fue firmado por el maestro Francisco Figuerola el día 5 de Agosto de 1599 23, lo que revela que el espacio en el que la misma se desarrolla debía estar ya concluido.

Por lo tanto, con fecha aproximada de agosto de 1599, el espacio del claustro debía estar preparado para afrontar el proceso de construcción del mismo. Este proceso fue relativamente rápido en comparación con otras partes del edificio, de manera que se iniciaría el 26 de noviembre de 1599, habiéndose prácticamente terminado en vísperas de la inauguración del 8 de febrero de 1604.

\section{Análisis formal del claustro del Colegio de Corpus Christi}

Es a partir de estos datos previos que es posible abordar el análisis formal y compositivo del claustro.

En el caso del claustro del Colegio del Patriarca, el manejo de un lenguaje arquitectónico estrictamente contemporáneo resulta notorio, ya que sus formas arquitectónicas evidencian la desnudez ornamental propia de la arquitectura española postescurialense; pero como previamente advertíamos, esta modernidad se superpone a un esquema compositivo de carácter marcadamente "anormativo". Ya hemos mencionado anteriormente la característica compositiva básica del claustro del colegio: el empleo de arcos directamente apoyados sobre las columnas, en detrimento del empleo del sintagma albertiano, cuyo uso estaba ampliamente difundido en la Península desde la construcción por Juan Bautista de Toledo y Juan de Herrera del escurialense Patio de los Evangelistas. De hecho podríamos decir que el claustro del Colegio del Patriarca representa, en términos compositivos, una apuesta de carácter conservador, llevada a cabo, en términos lingüísticos, en un lenguaje estrictamente moderno.

Sin embargo, hay que decir que el carácter "tradicional" del claustro del Colegio del Patriarca no representaba, en el momento de su construcción una incorrección linguiística, ni debía estar asociado a planteamientos arquitectónicos anacrónicos. El claustro del colegio, tal como fue construido, debía representar una de las opciones disponibles a finales del siglo XVI para la construcción de un espacio claustral, tan válida y coherente, como el recurso al sintagma albertiano. Su esquema compositivo respondía a una amplísima tradición, y eran numerosísimas las obras que se habían ejecutado siguiendo dicho esquema.

\footnotetext{
23 Archivo de Protocolos: Protocolo de Gaspar Joan Micó. Año 1599. Sign. 519.
} 
Lo que podemos afirmar es que se va a producir una progresiva implantación del esquema "albertiano" asentado, en gran parte, en el apoyo teórico que la tratadística le otorga. De hecho a sus evidentes virtudes compositivas para el control formal de la arquitectura muraria, une una coherencia en el empleo de los órdenes clásicos del que el apoyo del arco directamente sobre la columna carece, ya que en este último caso, el entablamento queda separado de la columna, produciendo una evidente distorsión de la proporcionalidad global del orden arquitectónico. Es posiblemente por esta razón que la tratadística renacentista opta, desde el principio, por ligar columna y entablamento, limitando el uso del arco a la pilastra y consecuentemente al muro. Alberti será el primero en proponer claramente este esquema como ortodoxo, como solución correcta para la construcción de galerías porticadas, si bien él mismo utilizará en la logia Rucellai el apoyo directo del arco sobre la columna.

En la tratadística renacentista no hay ningún autor que proponga la corrección del apoyo del arco en la columna, y las escasas ilustraciones que ejemplifican esta posibilidad, como las incluidas en la traducción realizada por Cosimo Bartoli al texto De Re Aedificatoria de Alberti (1550) ${ }^{24}$, o las láminas de intercolumnio del Medidas del Romano de Diego de Sagredo (1526) ${ }^{25}$, no pertenecen originalmente a los autores, sino que se trata de añadidos posteriores realizados por los editores, que reflejan el uso extendido de esta solución compositiva (figs. 7 y 8).

El propio Serlio se preocupa de criticar abiertamente esta posibilidad, de la que dice que: "si quissiesemos que solas las colunas redondas, hazer los arcos sera cosa falsissima: por que las quatro esquinas del Salmer, como affirman sobre una coluna redôda, cargan fuera del bivo" 26; y tanto en Vignola como en Palladio, los únicos sintagmas compositivos propuestos son el entablamento sobre las columnas (solución griega), y el arco entre columnas adosadas que soportan un entablamento (solución romana). Fruto de todo este apoyo teórico, ligado a una más correcta sintaxis compositiva de los órdenes clásicos, es la difusión del uso del sintagma albertiano, y la regresión del modelo tradicional.

En España no será hasta el empleo del esquema compositivo albertiano en el patio de los Evangelistas del Monasterio del Escorial, que podamos decir con propiedad, que este esquema se introduce en el panorama arquitectónico español, y que su presencia en nuestros claustros comienza a ser no sólo frecuente, sino incluso dominante. Si repasamos la cronología de obras significativas veremos que el claustro del Alcázar de Toledo fue trazado por Covarrubias el año 1550, y que su conclusión por parte de Francisco de Villalpando y Gaspar de Vega, hay que fijarla el año 1554. Por otra parte, del claustro de los Evangelistas del Escorial, cabe decir que las obras de construcción del edificio comienzan en fecha tan temprana como la de abril de 1562, y que a la muerte de Juan Bautista de Toledo el año 1567, la construcción del claustro estaba ya iniciada. No hay por tanto una diferencia cronológica importante entre el claustro valenciano y ambos prototipos. Además, pese que a partir de la construcción del Patio de los Evangelistas se produce un proceso de difusión de la aplicación del sintagma albertiano a la tipología claustral, no hay que olvidar que obras posteriores, como la Galería de Convalecientes del propio Monasterio del Escorial, o el palacio del Cardenal Espinosa en Marín Muñoz de Posadas, evidencian la pervivencia del empleo de esquemas compositivos más tradicionales. Por lo tanto, no cabe considerar al esquema compositivo del claustro del Patriarca como anticuado en términos peyorativos, sino que creemos que hay que ver en su uso la pervivencia en España de un esquema compositivo que tan solo dos décadas antes había empezado a ser sustituido. De hecho la elección de esta tipología claustral es voluntaria, y no puede ser atribuida a desconocimiento, ya que a los

24 AlberTI, Leon Battista. L'Architettura di Leonbatista Alberti: tradotta in lingua fiorentina da Cosimo Bartoli. Florencia, L. Torrentino, 1550. (ed. Cosimo Bartoli)

25 SAGREDo, Diego de. Medidas del Romano necessarias alos oficiales que quieren seguir las formaciones delas Basas Colunas, Capiteles, y otras piecas delos edificios antiguos. Toledo, Ramón de Petras, 1526. (Edición facsímil: Dirección General de Bellas Artes y Archivos, Instituto de Conservación y restauración de Bienes Culturales y Consejo General de Colegios Oficiales de Aparejadores y Arquitectos Ténicos. Madrid, 1986.)

${ }^{26}$ SERLIO, Sebastiano. Tercero y Cuarto Libro de Arquitectura. Edición de Juan de Ayala, Toledo,1552. (Ed. facsímil, Alta Fulla. Barcelona. 1990). Libro IV. fol.XXXI. 


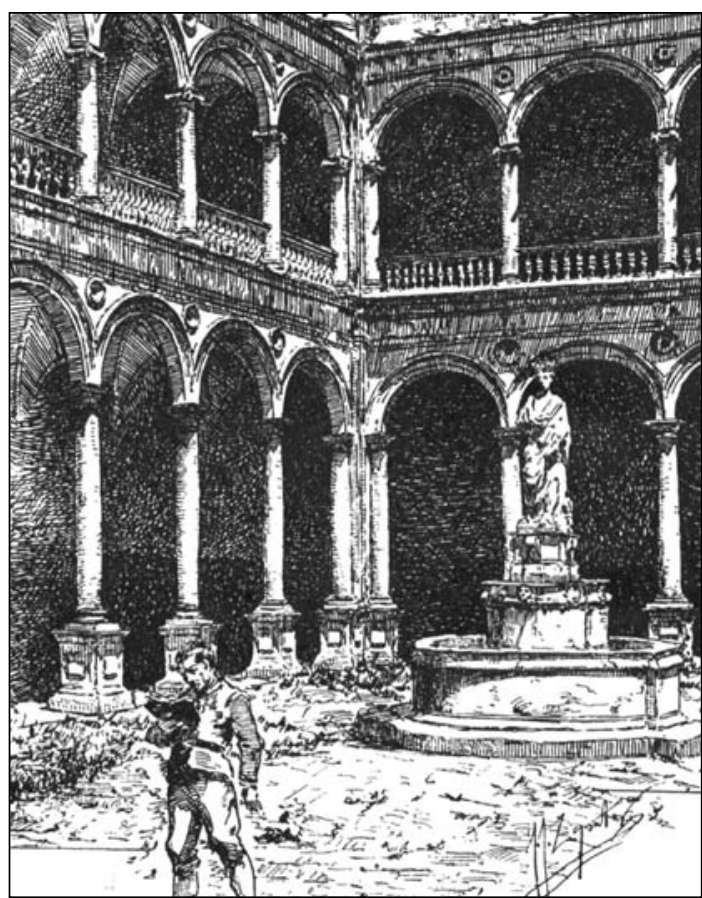

Fig. 5. Ilustración del claustro del Colegio contenida en la obra Valencia: Sus monumentos y artes, su naturaleza e historia de Teodoro Llorente (1887-1889).

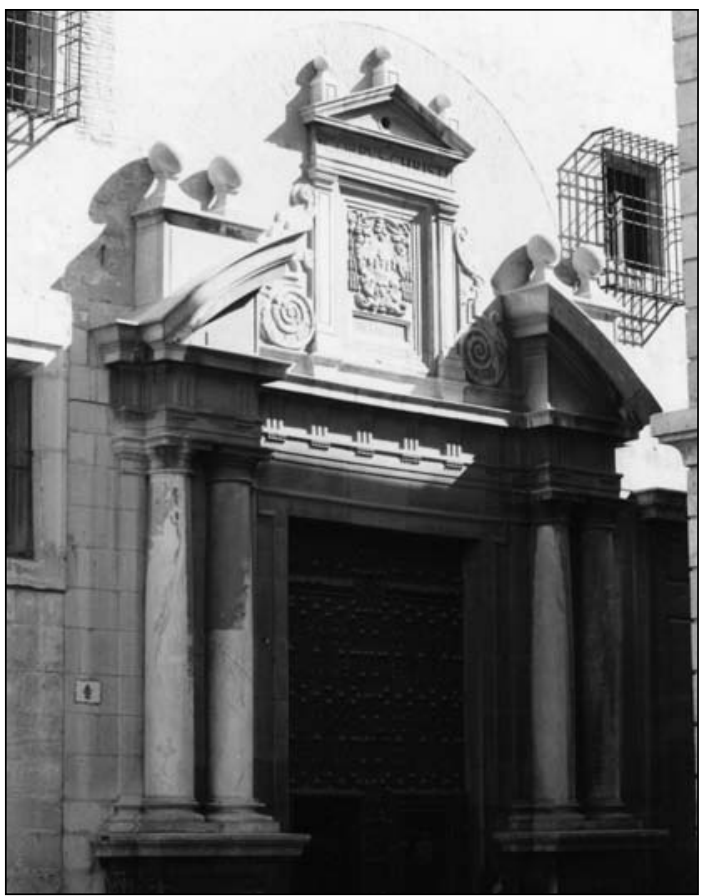

Fig. 6. Portada principal del Colegio de Corpus Christi, obra de Guillem del Rey (1603).

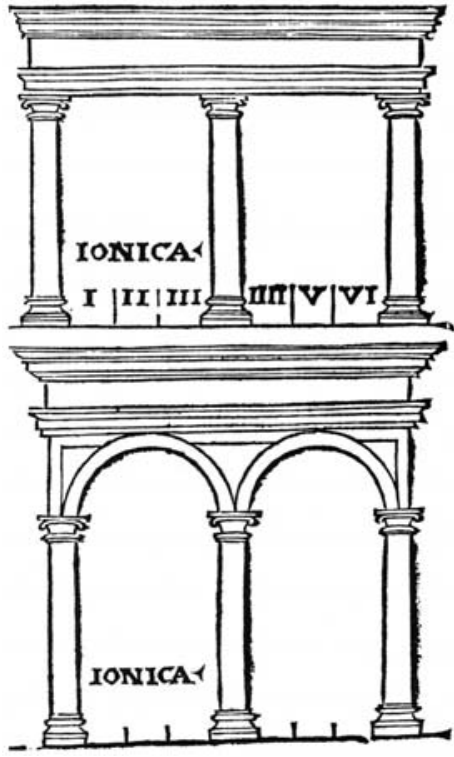

Fig. 8. Intercolumnio jónico añadido a la edición francesa de las Medidas del Romano de Diego de Sagredo (Raison Darchitecture antique, extraite de Victruue, et aultres enciens Architecteurs. Imp. Simón de Colines, aprox. 1537).
(1485). Sección de la basílica con superposición de los órdenes dórico y jónico, según la edición de C. Bartoli (Florencia, 1550). 
viajes del propio Patriarca Ribera a Madrid, hay que añadir que en el medio arquitectónico valenciano se estaba ejecutando contemporáneamente el claustro del Monasterio de San Miguel de los Reyes, en el que se estaba utilizando, literalmente, el modelo escurialense (figs. 9 y 10).

Son dos los condicionantes que, desde nuestro punto de vista, pudieron incidir de manera determinante en la disposición formal que se adoptó para el claustro del colegio: las necesidades dimensionales generadas por las obras previamente ejecutadas, y las dimensiones predeterminadas por el lote de columnas compradas. A partir de las obras previas, la altura de la galería inferior la determinarían tanto la altura a cubrir (altura de forjado), como las dimensiones concretas de las columnas compradas. La combinación de estos dos factores pudo conllevar la necesidad de utilizar un esquema compositivo tradicional, en el que la disposición de los arcos directamente apoyados sobre las columnas permitiese ganar altura, completándose las necesidades dimensionales con el uso de pedestales en la galería inferior, cuyas dimensiones derivarían, como veremos, de las necesidades dimensionales globales, y no de las directrices dimensionales marcadas por la propia teoría de los órdenes.

\section{El esquema compositivo general}

Para determinar las características compositivas y dimensionales del claustro se ha procedido a un levantamiento gráfico apoyado en técnicas fotogramétricas para garantizar la exactitud dimensional ${ }^{27}$, a partir del cual se ha procedido al análisis del conjunto.

Consideramos que las proporciones generales del claustro responden a la voluntad de acercamiento a la relación armónica $\varnothing(1.6181)$, mediante el sencillo recurso a los valores aproximativos de la serie de Fibonacci $(1,2,3,5,8,13,21 \ldots)$, cuyo empleo de valores consecutivos da una aproximación suficiente a la relación armónica. En el caso del Colegio del Patriarca el número de arcos de las galerías coincide con dos valores de la serie (5 y 8), cuya relación es 1,6 , valor muy cercano al del número $\varnothing$. Se conseguiría, mediante este sencillo recurso, cumplir los preceptos de la teoría arquitectónica renacentista y adaptarse al espacio físico realmente disponible.

Más considerables son las dificultades que se presentan al buscar el esquema compositivo subyacente en los alzados de las galerías del claustro, pese a lo cual sí que es posible determinar un esquema general del conjunto que respondería, nuevamente, a una sencilla operativa adaptada a las necesidades preexistentes. Este esquema es, al igual que se ha descrito para la planta, extremadamente sencillo, y afecta al alzado mayor del claustro. Es constatable que el ancho del alzado, medido nuevamente entre ejes de columnas, y el alto desde el suelo a la cornisa, están en relación de 2 a 1; es decir, el alzado, hasta la cornisa, es el doble de largo que de alto (fig 11).

Este podría ser el esquema dimensional básico, pero proponemos aceptarlo con las suficientes reservas, dado el carácter inseguro de este tipo de especulaciones. Además, desde este planteamiento se tendría forzosamente que considerar las proporciones del lado menor como residuales de las adoptadas para el lado mayor y para la planta, no respondiendo a ningún esquema dimensional propio.

Si bajamos al dimensionamiento de los elementos parciales, nos encontramos con la que creemos pudo ser una de las condiciones operativas básicas del diseño, ya que respondería a la preexistencia de una de las medidas fundamentales: la altura de la galería inferior de las galerías porticadas, construida, como vimos, con anterioridad a disponer efectivamente de las columnas compradas. Mientras que para algunos autores

${ }^{27}$ Las tomas fotográficas se han realizado mediante el uso de una cámara modelo Fotheo de la casa Zeis de Jena. Se han tomado tres tomas de una de las pandas del claustro para asegurar una correcta estereografía de las mismas, dispuestas de la siguiente manera: 1 toma central y dos tomas laterales. A continuación se ha realizado un apoyo topográfico, para el cual se ha utilizado como instrumentación básica un taquímetro de minutos TH42, y a partir de estos datos se ha procedido a la restitución fotogramétrica de las dimensiones del alzado del claustro. Para la restitución se ha utilizado un Planicom C-100. 
Fig. 9. Juan de Herrera. Alzado del ángulo suroeste del Patio de los

Evangelistas (1567-1568)

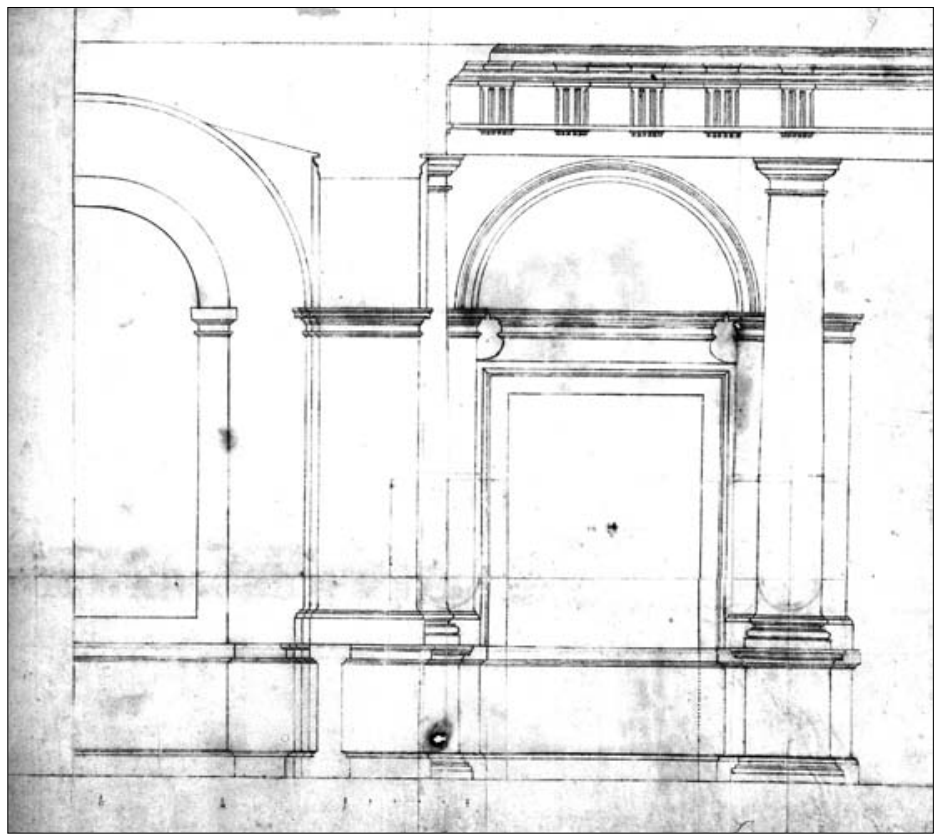

Fig. 10. Monasterio de San Miguel de los Reyes (Valencia). Sección del claustro sur.

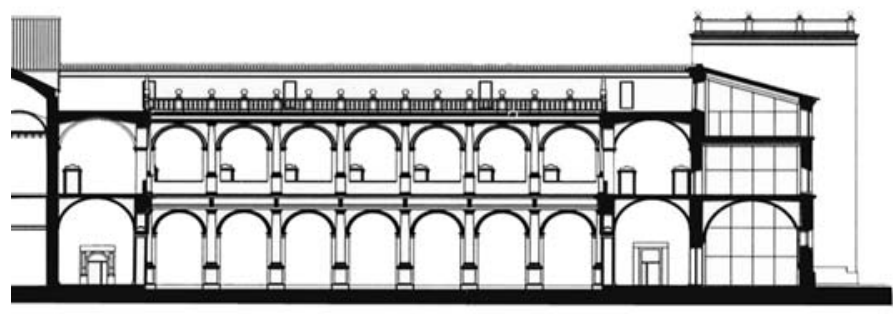

Fig. 11. Colegio de Corpus Christi (Valencia). Esquemas compositivos del claustro.

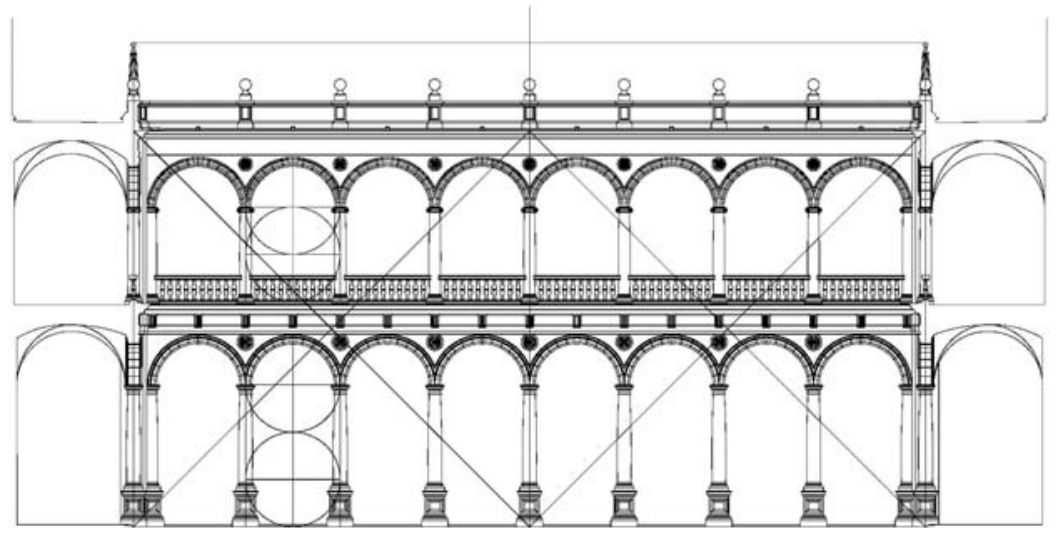

AEA, LXXX, 317, ENERO-MARZO 2007, 45-65, ISSN: 0004-0428 
las dimensiones de los ordenes desde su base, hasta la clave del arco, responden también a proporciones armónicas, y desde estas premisas iniciales descomponen la totalidad de las características dimensionales principales en secciones áureas 28 , la falta de exactitud dimensional sobre la que se asientan dichas hipótesis permiten descartar su validez. De hecho, en la realidad el esquema compositivo nos parece más sencillo y adquiriría lo siguientes valores, siempre referidos a la distancia entre ejes.

Orden dórico: Altura total / intercolumnio $=2$ y Altura capitel/ intercolumnio $=1.5$ Orden jónico. Altura total $/$ intercolumnio $=1.5$ y Altura capitel/ intercolumnio $=1$

Toda esta serie de relaciones facilita un esquema geométrico básico que define las proporciones del espacio claustral, que quedaría definido por los siguientes valores proporcionales:

1. Planta: Definida por las galerías mayor y menor, cuyo número de vanos ( 8 y 5 respectivamente), aproximan las dimensiones de la planta a la relación armónica definida por la sección áurea $(\varnothing=1.6181)$, medida a ejes de columnas.

2. Alzado mayor ( 8 vanos): Sus proporciones en alzado refieren a la proporción dupla, de manera que su anchura, medida nuevamente a ejes de pilares, es el doble de la altura del suelo del patio a la cornisa de remate.

3. Alzado menor (5 vanos): Sus proporciones serían las derivadas de las proporciones de la planta y el alzado principal. Partiendo de esta dimensiones previamente definidas, la proporción entre altura y anchura debe aproximarse al valor $\mathrm{R}=1,25$. En la realidad el valor es $\mathrm{R}=17.465 / 13.615=1,28$, lo que evidencia la validez del esquema, ya que la diferencia entre ambos valores es nuevamente producto del grosor de los machones laterales.

En lo referente a las dimensiones parciales de las diversas partes de las columnas resulta necesario tener en cuenta, tal como hemos dicho, las características proporcionales intrínsecas al propio sistema de órdenes; es decir, una vez fijadas las dimensiones generales del claustro, el conjunto de dimensiones parciales de los órdenes debería haber quedado ya definido. No obstante todo ello, el dimensionamiento de algunos elementos parciales, tales como los pedestales, podría ser el resultado del uso de esquemas geométricos simples. Este proceso de dimensionamiento parcial podría ser, básicamente el siguiente.

1. Se fija el intercolumnio haciéndolo coincidir con la altura de la columna jónica; es decir, aproximadamente $\mathrm{D}=3,225$.

2. El orden jónico se resuelve de manera directa, ya que al coincidir la altura de la columna y el intercolumnio, la altura total, al utilizar arco de medio punto, es necesariamente: $\mathrm{H}$ total $=1,5 \mathrm{D}$

3. El orden dórico tiene sus columnas ligeramente mayores que las del orden jónico, tal como corresponde teóricamente al dimensionamiento de órdenes superpuestos. A partir de estos valores, se toma como esquema una relación de altura total respecto del intercolumnio: $\mathrm{H}$ total $=2 \mathrm{D}$. La diferencia de altura de las columnas, con respecto a la altura total, se resuelve mediante el uso de los pedestales de la planta baja y, como veremos, al sobredimensionamiento de la cornisa.

Este esquema es, necesariamente una aproximación, y tiene el carácter de hipótesis. El hecho de haberlo planteado deriva de la inexistencia en la teoría arquitectónica renacentista de un sistema proporcional global para el esquema formal de galerías de arcos directamente apoyados sobre las columnas. Como consecuencia lógica de esta inexistencia teórica se deriva que al interponer un plano de arcos entre el capitel de

28 Puga Rodríguez, Mario. "Relaciones armónicas en el claustro del Patriarca (Colegio de Corpus Christi)" Revista del Colegio de Aparejadores y Arquitectos Técnicos de Valencia. n4, 1983. pp.16-25.

AEA, LXXX, 317, ENERO-MARZO 2007, 45-65, ISSN: 0004-0428 
la columna y el entablamento, las relaciones dimensionales del orden total -compuesto por pedestal, columna y entablamento-, se ven inevitablemente modificadas (fig. 13).

Finalmente, en lo relativo a las dimensiones generales del espacio claustral, conviene analizar la relación dimensional que debería producirse, según la teoría, entre las proporciones de los dos órdenes superpuestos. A este respecto, posiblemente sea Sebastiano Serlio el que aborde el problema con más profundidad. Serlio plantea cuatro posibilidades diferentes, aplicables a problemáticas diversas. En el caso del claustro del Colegio del Patriarca, los valores dimensionales implicados son los siguientes:

\begin{tabular}{lccc}
\hline & $\varnothing$ imoscapo & $\emptyset$ sumoscapo & H total \\
\hline Orden dórico & $0,47 \mathrm{~m}$ & $0,39 \mathrm{~m}$ & $3,65 \mathrm{~m}$ \\
\hline Orden jónico & $0,385 \mathrm{~m}$ & $0,36 \mathrm{~m}$ & $3,24 \mathrm{~m}$ \\
\hline
\end{tabular}

De los cuatro criterios propuestos por Serlio, y aplicando las dimensiones del claustro antes reseñadas, se cumple el segundo con una suficiente exactitud. Serlio propone hacer coincidir el diámetro del sumoscapo del orden dórico $\left(\varnothing_{\mathrm{s}=0.39)}\right.$ con el diámetro del imoscapo del orden jónico $(\varnothing \mathrm{i}=0.385)$. En el Colegio del Patriarca, las dimensiones correspondientes a estos valores son prácticamente coincidentes, lo que parece proponer el cumplimiento de este precepto serliano en el origen de las columnas; es decir Italia (fig. 12).

\section{El empleo de los órdenes clásicos: la formalización del esquema compositivo}

Del análisis dimensional desarrollado, cuya exposición pormenorizada no tiene cabida en este lugar, se desprende que los órdenes del claustro del Colegio de Corpus Christi no responden, en sentido estricto, a ninguno de los principales sistemas de la tratadística arquitectónica renacentista. Sin embargo, debemos precisar que existen importantes diferencias entre aquellas partes directamente compradas en Italia -basas, fustes y capiteles.-, y aquellas otras ejecutadas directamente por Guillem del Rey en Valencia.

\section{Las piezas italianas}

El análisis dimensional y formal de las partes de la columna, que son las que tienen su origen en el lote italiano comprado al duque de Pastrana (figs. 13 y 14), se caracterizan por tener sus diversas partes desproporcionadas entre sí, tomando como referencia la proporción que liga cada una de las partes del orden columnario al módulo principal del sistema: el radio de la columna en el imoscapo. Si analizamos las basas y los capiteles de ambos órdenes, concluimos que todos ellos están sobredimensionados, en mayor o menor grado, respecto al radio de la columna. Sin embargo, si procedemos a comparar las alturas relativas de basa, fuste y capitel, tanto del orden dórico, como del jónico, apreciamos que dentro de cada elementos parcial las molduras que lo componen, respetan la proporcionalidad entre ellas que dicta el sistema dimensional de Serlio.

Cabe por ello concluir, que la desproporción que se aprecia al aplicar directamente cada uno de los sistemas teóricos a las medidas existentes en el claustro, deriva principalmente de una falta de correspondencia entre el diámetro de la columna en la base, y el resto de elementos que lo componen; es decir, que los fustes de las columnas -tanto dóricas como jónicas- son ligeramente estrechos, mientras que la proporcionalidad interna del conjunto, y la proporcionalidad individual de las partes, es esencialmente correcta.

De hecho, si analizamos las características formales y dimensionales de las partes de la columna -basa, fuste y capitel-, comprobamos que, sin cumplir estrictamente las dimensiones estipuladas por los diferentes tratadistas, responden básicamente a la ortodoxia del sistema. Las variaciones son siempre puntuales y afectan a las dimensiones de pequeñas molduras, pero respetando tanto el diseño formal, como la proporcionalidad básica de todos los elementos (figs. 15 y 16). 


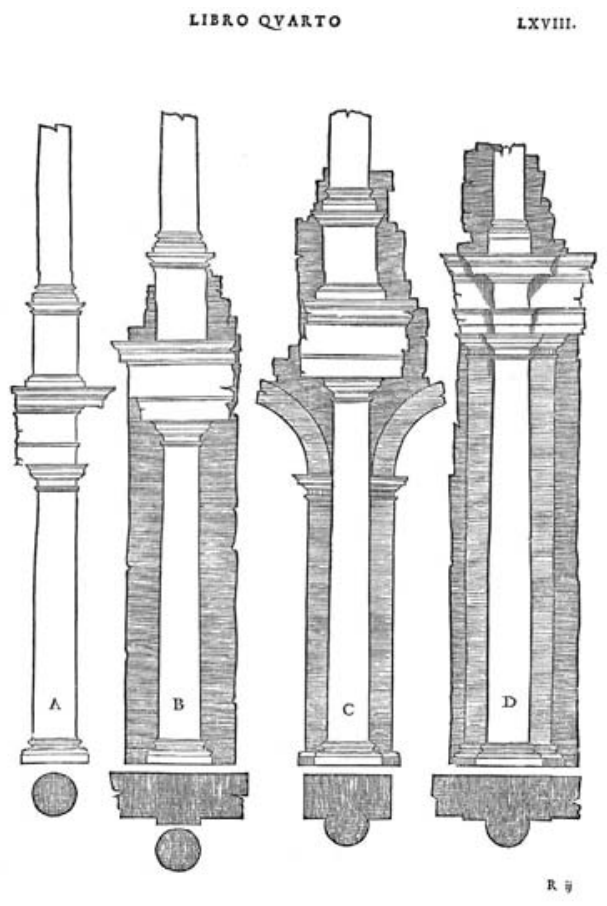

Fig. 12. Sebastiano Serlio, Libro Cuarto (1537). Fol. LXVIII. Superposición de órdenes.

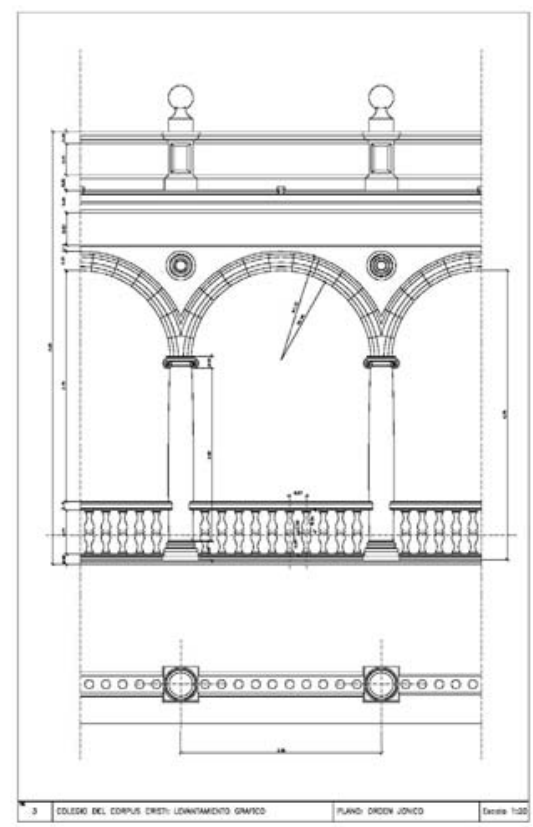

Fig. 14. Colegio de Corpus Christi (Valencia). Levantamiento del orden jónico del claustro.

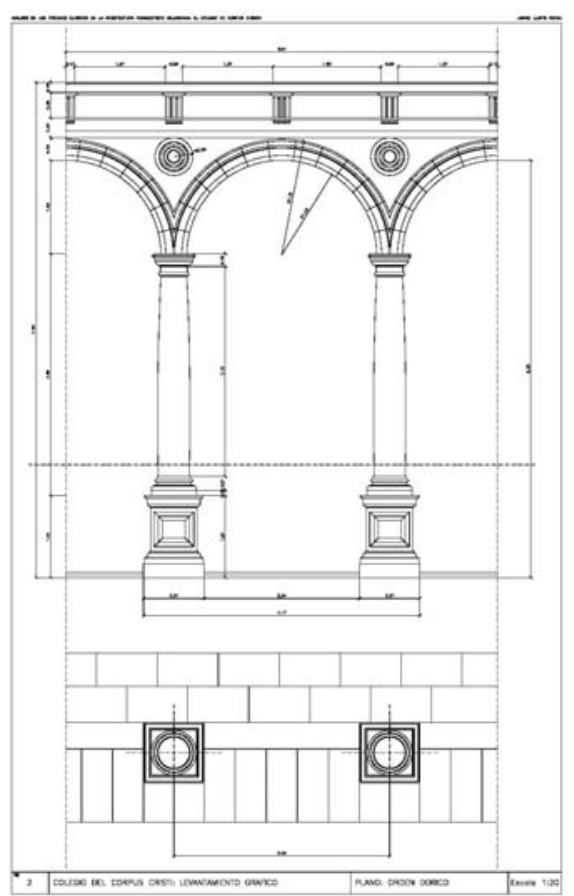

Fig. 13. Colegio de Corpus Christi (Valencia). Levantamiento del orden dórico del claustro.

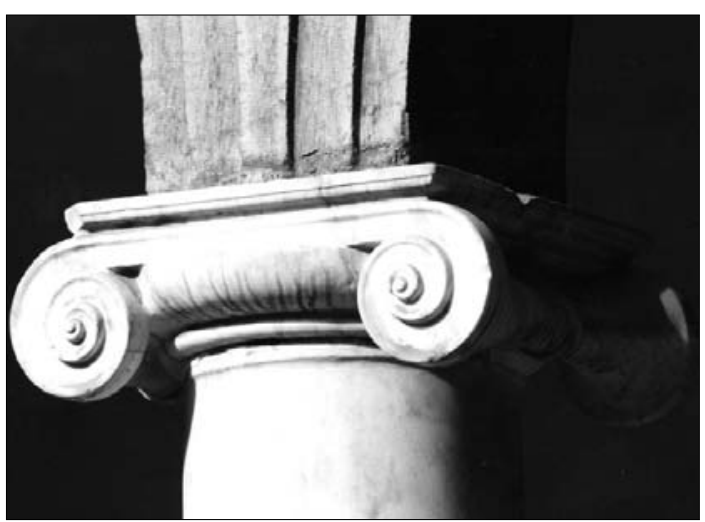

Fig. 15. Colegio de Corpus Christi (Valencia). Capitel jónico del claustro, perteneciente al lote de columnas adquiridas en Italia por el Duque de Pastrana. 


\begin{tabular}{lll}
\hline ORDEN & ELEMENTO & INFLUENCIA \\
\hline DórICO & Proporciones generales & Serlio \\
\hline Molduras del fuste & Vignola \\
\hline$\varnothing$ sumoscapo /Ø imoscapo & Todos excepto Palladio \\
\hline Basa & Serlio (los demás similar) \\
\hline Cánitel & Serlio \\
\hline PónICO & Serlio \\
\hline & Proporción de superposición & Serlio \\
\hline Molduras del fuste & Serlio \\
\hline Basa & Alberti y Serlio \\
\hline Capitel & $\begin{array}{l}\text { Serlio, Vignola y Palladio con } \\
\text { deformaciones parciales }\end{array}$ \\
\hline
\end{tabular}

Se aprecia un claro predominio de la influencia serliana sobre el resto, habida cuenta que en numerosas ocasiones (p.e. la basa dórica), se producen claras similitudes entre los diferentes autores. Las razones que pueden explicar esta paradójica situación, en la que la principal incorrección dimensional estriba precisamente en la medida del parámetro básico del sistema -el radio del imoscapo-, mientras que los elementos parciales respetan -pese a incorrecciones puntuales- la ortodoxia formal o dimensional de la teoría sobre los órdenes, podrían radicar en alguna de las explicaciones siguientes: La primera hipótesis propone que las dimensiones originales de las piezas italianas no respondan exactamente a las actuales, y que las operaciones de saneamiento y restauración a las que fueron sometidas tras estar largo tiempo enterradas provocasen una modificación de las mismas. Concretamente está documentado que las basas dóricas hubieron de ser serradas para ajustarlas a las proporciones ortodoxas ${ }^{29}$, y se sabe que los fustes de las columnas hubieron de ser reparados y limpiados. Podría ocurrir, por lo tanto, que las tareas de limpieza de los fustes, y la consiguiente reparación de los mismos, fuesen acompañadas de una reducción sensible del grosor, que explique esta delgadez relativa de los fustes respecto de las otras piezas.

Otra posible explicación estribaría en un posible origen heterogéneo de las diversas piezas, que elegidas de manera que cumpliesen suficientemente la proporcionalidad teórica, no se correspondiesen totalmente entre sí. Esta explicación justificaría las múltiples distorsiones puntuales y los desajustes parciales que se aprecian entre las mismas, de manera que el claustro del Colegio sería el producto de una multiplicidad de actuaciones heterogéneas.

\section{Las partes españolas talladas por Guillem del Rey}

Un segundo grupo de elementos formales (figs. 17, 18, y 19) no tenía su origen en Italia, sino que fueron específicamente tallados por el cantero Guillem del Rey para el claustro del colegio, tal como evidencia el contrato por él firmado. Dentro de este grupo tenemos que englobar todas las partes realizadas en piedra de Ribarroja, es decir, los cantones, los pedestales dóricos, los arcos y el entablamento dórico, los arcos y el entablamento jónico, el antepecho superior, y las bolas y pirámides del remate. Estas partes evidencian una mayor dependencia de los esquemas compositivos globales -trazados geométricos del conjunto-, en detrimento de la proporcionalidad interna del sistema de los órdenes. Por esta razón, mientras las columnas evidenciaban en sus partes un cumplimiento suficientemente ortodoxo de las dimensiones teóricas, y una cierta homogeneidad de las fuentes que influían en su diseño (Serlio), las partes talladas por Guillem del Rey

29 "Ittem ha de serrar y cortar el dicho Guillem del Rey los plintos de todas las baças de la orden dorica que es la orden de abaixo del dicho claustro para que queden en su devida proporcion conforme la dicha orden dorica requiere y los plintos de marmol hayan de ser y sean del dicho Rettor.". En "Concierto firmado por Guillem del Rey para la construcción del claustro del Colegio del Corpus Christi”. A.C.CH.: I, 6, 1, 8. 
se caracterizan por la heterogeneidad de las influencias formales, y por justificar sus dimensiones en los esquemas geométricos globales, antes que por proporcionarse según las medidas ortodoxas correspondientes a su propio orden. Esto es especialmente evidente en el caso del pedestal dórico, cuyas dimensiones, teóricamente heterodoxas, parecen tener su justificación en la altura que le permitía la adopción de un esquema compositivo duplo para el conjunto del orden dórico.

Así pues, es precisamente en este grupo de elementos tallados por Guillem del Rey, en el que van a concentrarse las principales distorsiones dimensionales del claustro, pero creemos que no tanto por desconocimiento teórico del arquitecto, como porque son precisamente estos elementos formales los que se ven más directamente afectados por la heterodoxia que suponen el apoyo directo de los arcos sobre las columnas. Si los pedestales derivaban precisamente del esquema geométrico global del orden dórico, y el antepecho de remate es producto de la necesidad funcional de protección, el resto de los elementos de este grupo son precisamente los arcos -causa principal de las heterodoxias dimensionales-, y los entablamentos -la parte más afectada por las mismas-.

Respecto al análisis dimensional de los entablamentos, quisiéramos constatar que sus dimensiones se proporcionan sobre la dimensión de las columnas, sin tener en cuenta las dimensiones de los arcos interpuestos entre ambos elementos. Si cabe, se apreciaría una cierta tendencia a sobredimensionar ligeramente su altura, como si se quisiera compensar, en parte, el aumento de altura que suponen los arcos sobre el conjunto. Consideramos que esto revela una tendencia hacia un intento de proporcionar ortodoxamente el sistema, dentro de las limitaciones evidentes que su composición formal tradicional conlleva.

Por otro lado, resulta difícil establecer influencias formales claras y precisas, ya que algunos elementos no responden, en modo alguno, a las directrices teóricas de la tratadística. Este aspecto se constata, sobre todo, en el entablamento jónico de la galería superior, extremadamente simplificado y sin parangón en la tratadística analizada. Por el contrario, el pedestal dórico, heterodoxamente dimensionado, respondería formalmente a las propuestas de autores casi contemporáneos como Vignola o Arphe (fig. 20).

Por todo ello podemos decir que esta aparente heterodoxia dimensional de las partes de los órdenes efectuada en Valencia, y la multiplicidad de influencias formales que se aprecia en dichos elementos, debe ser considerada más como una solución concreta a problemas concretos, que como una prueba de desconocimiento de la teoría del sistema. La desnuda “cornisa bastarda" que remata el orden jónico y el conjunto, es un producto típico del reduccionismo formal, de aires vignolescos, que caracteriza la arquitectura española de finales del siglo XVI (fig. 21). De hecho si hay que precisar la predominancia de alguna influencia dominante en todo este segundo grupo de elementos formales, sería precisamente la de Vignola, frente la preponderancia serliana de las piezas italianas. A esta última conclusión no puede ser ajeno el desfase cronológico que presumiblemente existe entre la talla de ambos grupos, ya que si la obra del claustro está datada de 1599 a 1603, en pleno predominio del reduccionismo formal de Vignola en nuestro panorama arquitectónico, la talla de las columnas italianas debió ser considerablemente anterior, lo que facilitaría que la obra de Serlio ejerciese todavía una mayor importancia.

Finalmente, decir que la escueta desnudez formal de estos elementos podría tener como referencia formal, el propio gusto del Patriarca Ribera, y la estructura morfológica de su propio palacio familiar sevillano. Si ya en dicho palacio -más concretamente en las obras del jardín Arqueológico realizadas entre los años 1568 y 1571-, se anticipan la desnudez ornamental que caracterizará el diseño del claustro del colegio valenciano, la estrecha adscripción del Patriarca Ribera a los principios tridentinos, y la influencia escurialese a la que el propio Patriarca se vería sometido debido a su estrecha relación con la corte filipina, completarían el círculo de infuencias formales que dan como resultado la desnuda sobriedad de la obra valenciana (figs. 22 y 23).

\section{Conclusiones}

La primera conclusión que se desprende del análisis realizado, es que no es posible encontrar un modelo formal o dimensional único y coherente que explique, en su conjunto, el empleo de los órdenes clásicos en el claustro del Colegio del Patriarca, y, por generalización, en el conjunto del edificio. Los condicionantes 

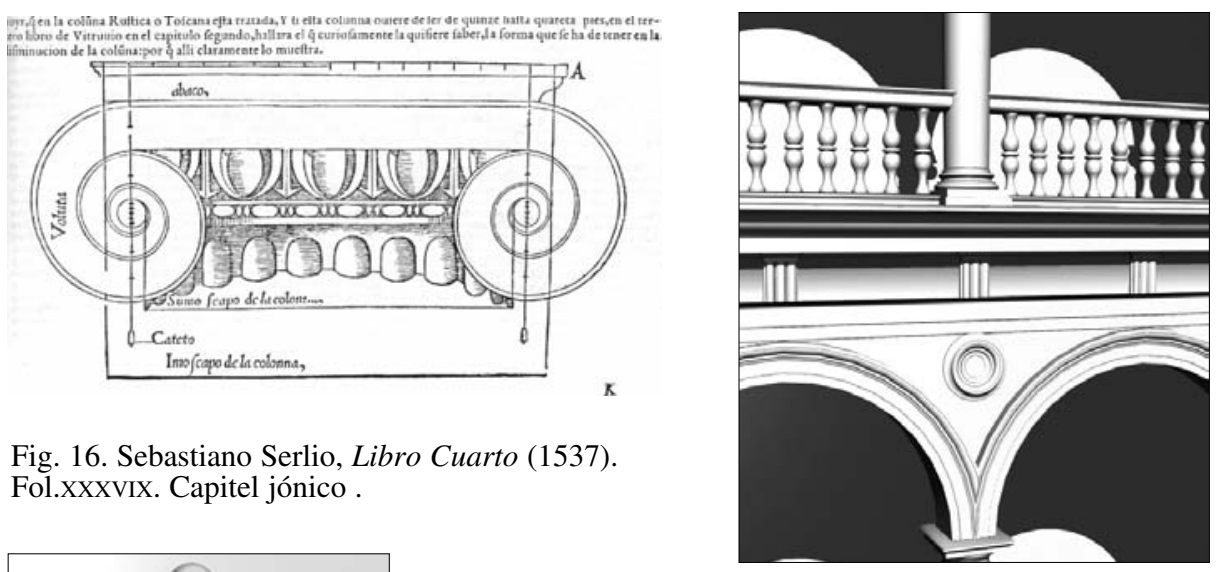

Fig. 16. Sebastiano Serlio, Libro Cuarto (1537). Fol.xxXVIX. Capitel jónico .

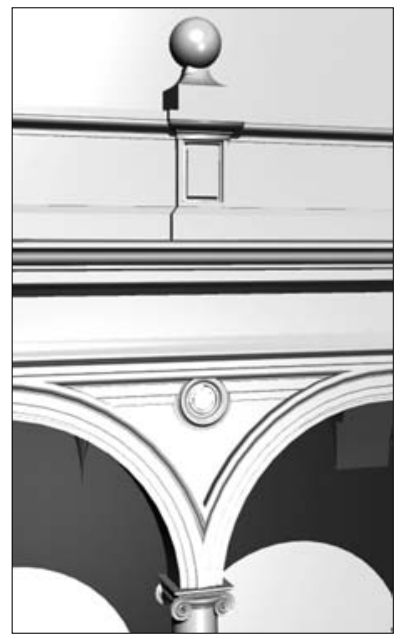

Fig. 18. Colegio de Corpus Christi (Valencia). Modelización tridimensional del entablamento jónico del claustro.

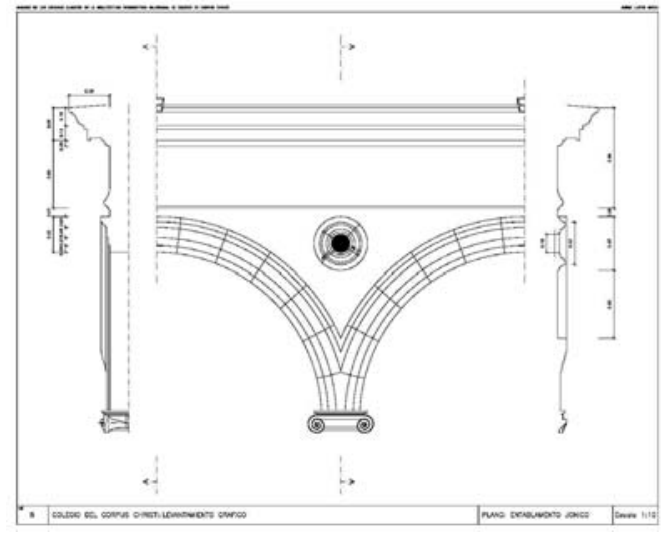

Fig. 19. Colegio de Corpus Christi (Valencia). Levantamiento del entablamento jónico del claustro.

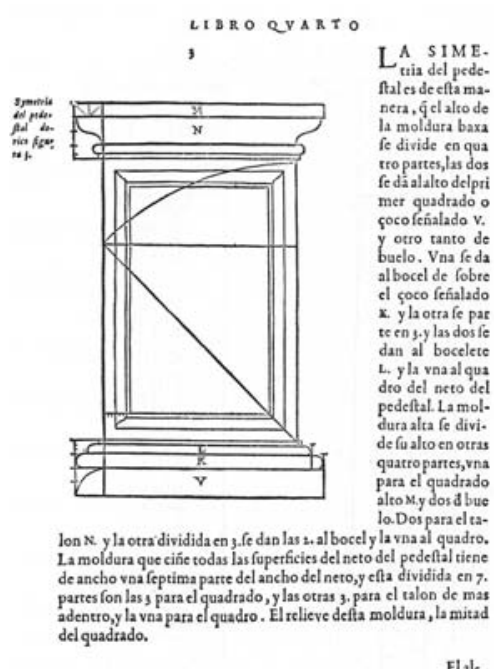

Fig. 20. Joan de Arphe y Villafañe. De varia conmesuration para la escultura y arquitectura. (1585-1587). Pedestal dórico. 
previos sobre los que asienta el proceso de diseño del espacio claustral son muy diversos, y parten de sus referentes formales iniciales que condicionan profundamente el dimensionamiento de los elementos arquitectónicos que lo componen. Hay que tener en cuenta que en el claustro del colegio es virtualmente imposible cumplir ningún sistema proporcional teórico, porque ninguno de dichos sistemas prevé la utilización de los arcos directamente apoyados sobre las columnas, y la separación física del entablamento respecto de los capiteles ${ }^{30}$. Desde esta premisa inicial, hay que asumir que el tracista se veía enfrentado a una serie de problemas formales y dimensionales que, al no estar contemplados en la teoría arquitectónica existente, debía solucionar mediante el recurso a la tradición arquitectónica de la tipología claustral, o mediante la concepción de recursos propios particulares para esta obra concreta (fig. 24).

A este condicionante inicial, derivado de la propia concepción arquitectónica del desconocido tracista, se le une un condicionante dimensional derivado del proceso constructivo de la obra: el aprovechamiento de un lote de columnas que el Patriarca Ribera compró a la familia del duque de Pastrana, que habían sido adquiridas en Italia.

El uso de este lote condiciona profundamente, tanto como la propia concepción formal del claustro y la secuencia constructiva del resto del edificio, el proceso de ideación arquitectónica del espacio claustral, ya que introduce un parámetro dimensional previo al que hay que adaptar el dimensionamiento del conjunto del espacio. Hay que pensar que en un sistema formal tan rígidamente estructurado en las relaciones proporcionales que ligan los diversos elementos que lo componen, la dimensión de la columna implica a todos y cada uno de los miembros arquitectónicos que entran en relación con ella; y en teoría condiciona tanto la altura total del conjunto (superposición de órdenes), como las dimensiones en planta del mismo (derivado del intercolumnio, y del número de columnas disponibles). Es por ello que al abordar el análisis formal anticipábamos la teoría de que es posible que el recurso a la composición tradicional de arco directamente apoyado sobre columna, estuviésemos asistiendo al recurso proyectual para conseguir una mayor altura del claustro a partir de las reducidas dimensiones de las columnas preexistentes.

Como se puede ver, son muchos los condicionantes que influyen intensamente en el empleo de los órdenes clásicos en el claustro del Colegio del Patriarca, hasta el punto que podemos definir el diseño de este espacio, más como un proceso de adaptación, que como un proceso de creación. El análisis del claustro evidenciaría el conocimiento del sistema de órdenes clásicos y los mecanismos de control del espacio por medio de dicho lenguaje en el medio arquitectónico valenciano de finales del siglo XVI, más por la capacidad de manipulación del lenguaje y por la capacidad de reinterpretar los elementos formales predeterminados, que por mostrar los mecanismos de diseño de nuestros arquitectos cuando se enfrentaban, sin condicionantes previos, a la necesidad de articular un espacio mediante el empleo de las formas del lenguaje clásico.

El análisis del empleo del sistema de los órdenes clásicos en el claustro del Colegio del Patriarca ha evidenciado el uso simultáneo de dos sistemas de control proporcional por parte de los arquitectos renacentistas. El primero hace referencia al empleo de esquemas geométricos para el control de la forma en su conjunto, y constituye el mecanismo que más ampliamente ha llamado la atención de los estudiosos de la arquitectura renacentista. Su uso sistemático no sólo ha sido evidenciado en numerosos estudios parcia${ }^{l e s}{ }^{31}$, sino que es perfectamente rastreable en la propia tratadística renacentista. El segundo, el sistema de

${ }^{30}$ En el libro de Diego de Sagredo sí que aparece ilustrada esta solución compositiva para porticos de arcos, pero se trata de ilustraciones añadidas al original de Sagredo con motivo de su primera edición francesa, y no constiruye en modo alguno parte de su pensamiento arquitectónico, sino una estrategia editorial encaminada a aumentar la divulgación de la obra, mediante la ilustración de una solución compositiva que careciendo de soporte teórico conveniente, estaba amplísimamente divulgada en toda Europa.

${ }^{31}$ La teoría a este respecto es numerosísima, y no constituye el motivo de nuestro estudio, por lo que tan solo citaremos como textos básicos en esta tendencia los ya tradicionales: WITTKOWER, Rudolph. La arquitectura en la edad del humanismo. Nueva Visión, Buenos Aires, 1958; GHYKA, M.C. El número de oro. Ritos y ritmo pitagóricos en el desarrollo de la civilización occidental. Poseidón, 2 vols. Buenos Aires, 1986; ScHOLFIELD, P.H. Teoría de la proporción en arquitectura. Labor, Barcelona, 1971. 


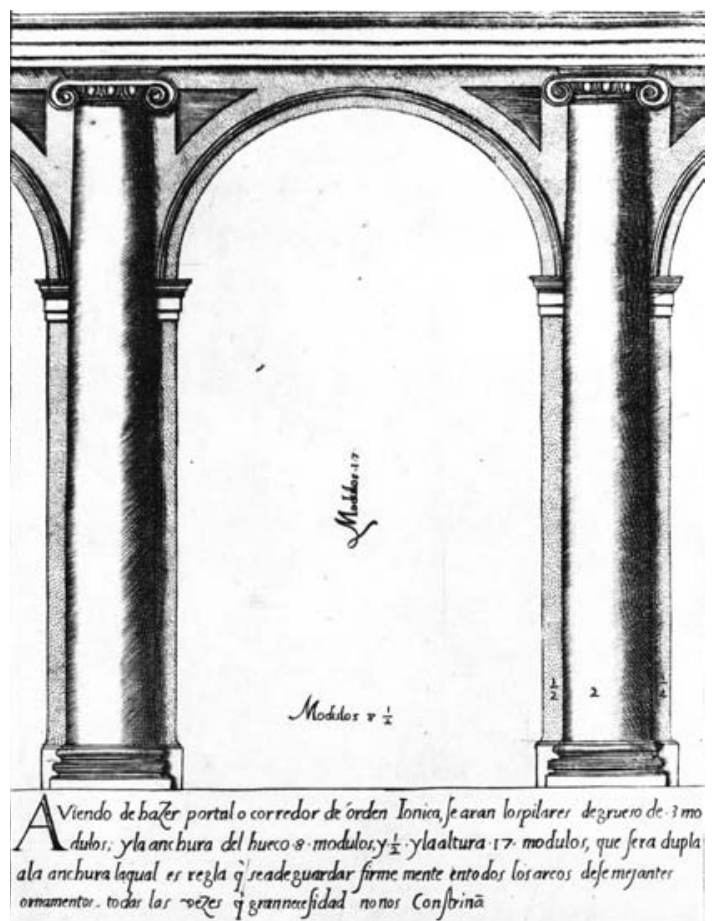

Fig. 21. Giacomo Barozzi da Vignola, Regola delle cinque ordini d'architettura (1562). Intercolumnio jónico.

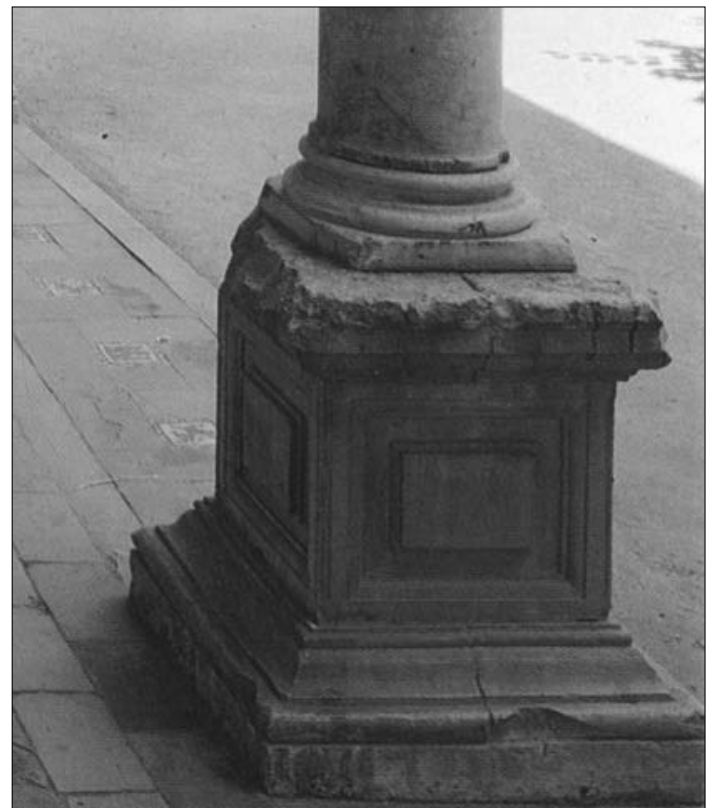

Fig. 23. Benvenuto Tortello. Pedestal del Jardín Arqueológico de la Casa de Pilatos de Sevilla (1568-1571).

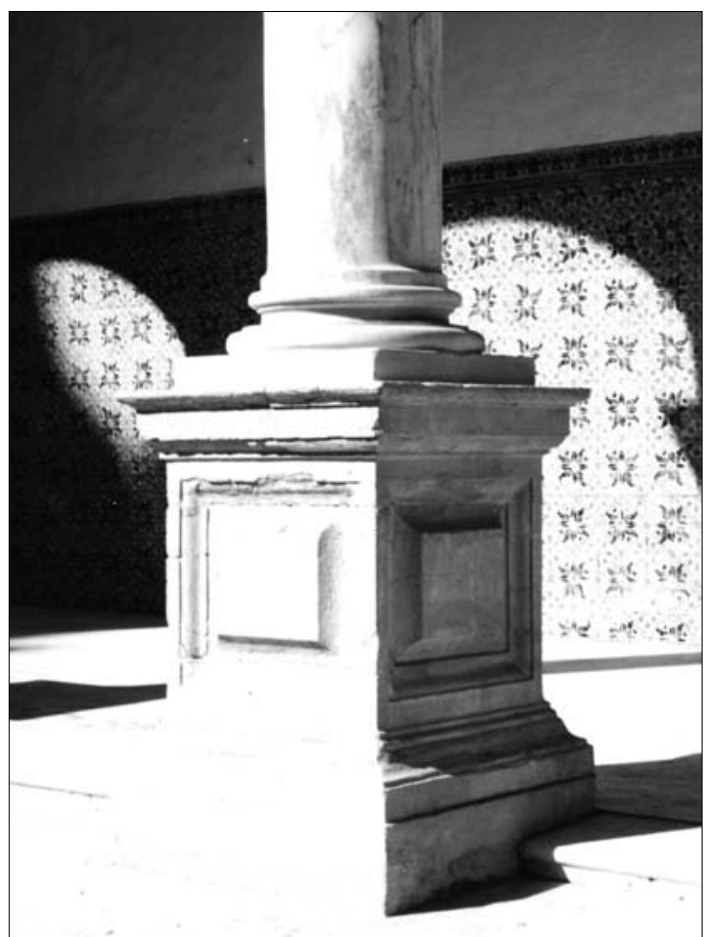

Fig. 22. Colegio de Corpus Christi (Valencia). Pedestal dórico del claustro.

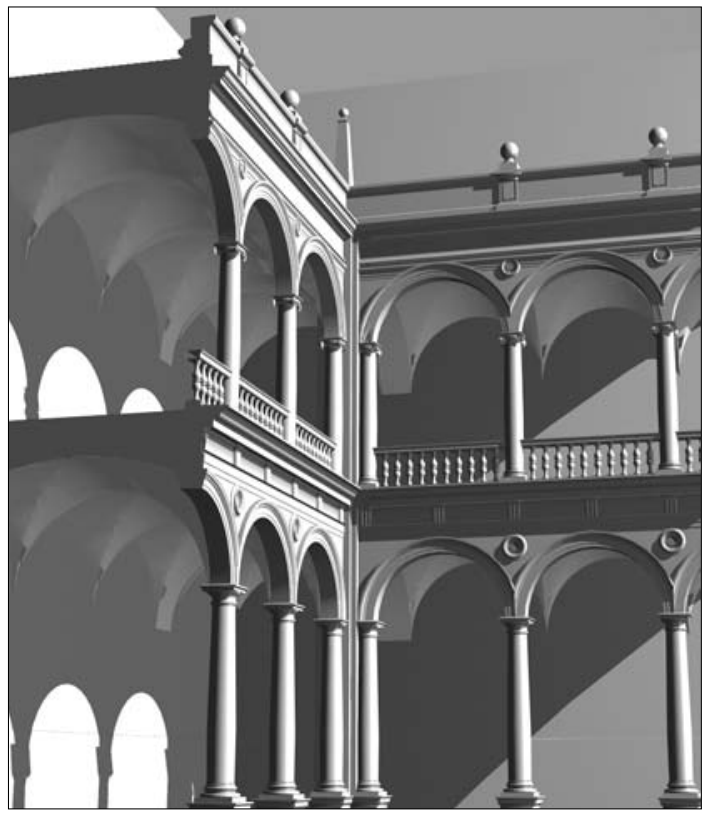

Fig. 24. Colegio de Corpus Christi (Valencia). Modelización tridimensional del claustro. 
los órdenes clásicos, juega un papel fundamental en el esquema del Clasicismo arquitectónico, en tanto que arquitectura regida por sistemas proporcionales basados en criterios armónicos. Este tipo de esquemas geométricos constituyen la base proyectual de la arquitectura renacentista (o al menos su ideal), pero para evidenciarla se hace necesario el recurso al empleo de los órdenes clásicos, de los elementos normalizados que constituyen su lenguaje básico. En su plena legibilidad los órdenes clásicos evidencian el esquema proporcional subyacente, en vez de ocultarlo en la multiplicidad formal que caracteriza los elementos formales góticos. Pero a su vez, el propio sistema de los órdenes arquitectónicos es portador de una proporcionalidad interna, de un sistema de medidas que condiciona en gran parte las medidas generales del espacio.

El análisis efectuado en el Colegio de Corpus Christi evidencia esta interacción, ya que algunas de las medidas parciales no pueden explicarse desde la proporcionalidad interna del sistema de órdenes, sino que parecen directamente derivadas de la existencia de proporciones geométricas generales. Es el caso, por ejemplo, de la altura de los pedestales dóricos, que requerirían el recurso a la proportione quadrata que Sebastiano Serlio especifica para el orden toscano, pero que desde nuestro punto de vista derivaría directamente del empleo de un esquema geómetrico de razón 1:2 para el conjunto formado por pedestal, columna y arco. La altura total del pedestal se derivaría, según esta hipótesis, de esquemas proporcionales generales, y no de su modelización según las proporciones de ninguna de las propuestas para el orden dórico contenidas en los tratados. Es precisamente esta interacción entre esquemas proporcionales globales, y sistemas de medidas internas de los propios órdenes arquitectónicos, la que la tradición historiográfica renacentista tiende a olvidar, mientras que desde nuestro punto de vista es el único supuesto desde el que cabe entender el proceso de dimensionamiento y el empleo de los órdenes clásicos que genera el claustro del Colegio del Patriarca tal y como hoy lo conocemos.

Finalmente, una consideración al hilo de este proceso. El equilibrio entre uno y otro sistema es un tema necesariamente subjetivo, que depende, única y exclusivamente, de la sensibilidad personal del arquitecto que traza la obra. En este sentido, la personalidad del arquitecto resulta determinante, y su papel en el proceso es imprescindible para comprender los sutiles equilibrios, y las vulneraciones voluntarias, que el análisis realizado propone. El análisis del empleo de los sistemas proporcionales propios de los órdenes arquitectónicos evidencia, tanto su aplicación real y concreta por los arquitectos renacentistas, como las propias limitaciones de esta vía de análisis. El recurso a este tipo de análisis nos ha permitido cubrir algunas lagunas que se evidenciaban en el empleo exclusivo de mecanismos geométricos globales, pero no pretende sustituir el papel de aquellos, sino complementarlos.

Quisiéramos concluir diciendo que el uso de los órdenes en el Colegio de Corpus Christi está fuertemente condicionado por las particulares condiciones en las que fue efectuada su construcción, y por la multiplicidad de influencias y condicionantes previos a los que hubo que satisfacer durante el proceso. Fruto de todo ello es la imposibilidad de definir el cumplimiento íntegro de algún sistema dimensional concreto, y la constatación de que son diversas las influencias que se aprecian en los elementos formales que lo conforman.

La verdadera lección del claustro del Colegio del Patriarca, radica en la capacidad de quien lo concibió para conseguir una obra total y absolutamente clásica a partir de un esquema compositivo "no canónico", y de unos materiales heterogéneos. Su análisis nos muestra cómo es posible emplear los órdenes sin adscribirse rígidamente a la ortodoxia, sin por ello caer en la heterodoxia, consiguiendo realizar en el camino la que ha sido calificada por F. Chueca como "la obra escuetamente clásica más considerable, por sus intrínsecas bellezas arquitectónicas, de todo Valencia" 32.

32 Chueca GoItia, Fernando. Arquitectura del siglo XVI. Vol XI de “Ars Hispaniae” Madrid, 1953. p.306. 